\title{
Urban modelling for evaluating photovoltaic potential through solar radiation incidence
}

XXIV International Conference of the Iberoamerican Society of Digital Graphics Medellin | Colombia

\author{
Andrea Verri Bastian \\ Universidade Federal da Bahia | Brasil | andrea.bastian@ufba.br \\ Jarede Joaquim de Souza Filho \\ Universidade Federal da Bahia | Brasil | jaredejoaquim@gmail.com \\ Júlia Assis de Souza Sampaio Garcia \\ Universidade Federal da Bahia | Brasil | juliassis98@gmail.com
}

\begin{abstract}
This study aims to better ascertain the influence that urbanistic parameters exert on the production of solar photovoltaic energy regarding different contexts in the city. Modifications implemented between the years of 2012 and 2016, especially on variables such as Maximum Lot Coverage, Floor Area Ratio, and Setbacks, have been evaluated through virtual models that cover areas in three different city districts. Amongst other implications, an increase in the area occupied by the buildings, as well as a decrease in the distance between them, occurred, causing more mutual shading and the loss of the photovoltaic potential associated with the building envelope.
\end{abstract}

Keywords: Urbanistic parameters; Photovoltaic solar energy; Virtual models; Architecture; Urbanism.

\section{INTRODUÇÃO \\ ENERGIA E CIDADE}

O crescimento da população urbana apresenta desafios cada vez maiores para o planejamento das cidades. $010^{\circ}$ Fórum Urbano Mundial (WUF), que teve como tema: Cidades de Oportunidades, Conectando Cultura e Inovação, chama a atenção para a Urbanização como uma oportunidade para a consolidação de um desenvolvimento humano com baixo impacto ambiental. As novas tecnologias associadas às tradições e culturas locais seriam um caminho para superar os problemas que assolam as cidades atuais (ONU, 2020). Sendo assim, o $10^{\circ}$ WUF está em consonância com a Nova Agenda Urbana (NUA) de 2016, segundo a qual "até 2050, esperase que a população urbana quase duplique, fazendo da urbanização uma das tendências mais transformadoras do século XXI" (ONU, 2016, p. 3).

Nesse contexto, os estudos e inovações da Arquitetura e do Urbanismo, associados a outras áreas do conhecimento apresentam um papel central nos rumos a serem tomados para o desenvolvimento das cidades. Vale destacar que, entre os vários tópicos que se interligam no planejamento urbano, o presente artigo aborda aquele que diz respeito às fontes de energia renováveis, mais especificamente a geração distribuída de energia solar fotovoltaica. Essa fonte de energia tem ganhado cada vez mais espaço nas edificações do meio urbano, já que, além de não produzir emissões durante a geração, o aperfeiçoamento e difusão dos equipamentos empregados no processo têm reduzido seus custos (Associação Brasileira da Indústria Elétrica e Eletrônica, 2012). Tais características contentam as diretrizes da NUA (2016), como mostrado a seguir:

\begin{abstract}
"54. Comprometemo-nos com a geração e o uso de energia renovável e economicamente acessível e com serviços e infraestrutura de transporte sustentáveis e eficientes, sempre que possível, alcançando os benefícios da conectividade e reduzindo os custos financeiros, ambientais e de saúde pública advindos da mobilidade ineficiente, dos congestionamentos, da poluição do ar, do efeito de ilhas de calor urbano e da poluição sonora. Comprometemonos também a prestar especial atenção às necessidades energéticas e de transporte de todas as pessoas, particularmente os mais pobres e os que vivem em favelas e assentamentos informais. Observamos também que as reduções nos custos de energia renovável fornecem a cidades e assentamentos humanos uma ferramenta eficaz para diminuir os custos de fornecimento de energia." (ONU, 2016, p. 15)
\end{abstract}

A geração de energia solar fotovoltaica, no ambiente urbano, depende da correlação entre fatores como, o desenho da cidade, com os parâmetros de uso e ocupação do solo, e com as novas tecnologias da área. Sendo assim, vale destacar que, a projetação arquitetônica em ambiente digital tem ganhado cada vez mais ferramentas, aproximando o projeto de sua tectônica. Os programas BIM (Building Information Modeling), por exemplo, permitem a integração entre o projeto arquitetônico e os projetos complementares, de forma a reduzir ou evitar problemas durante a execução da obra. No âmbito urbano, também é possível utilizar diversas ferramentas da gráfica digital para antever o desempenho das edificações, sejam eles legais, ambientais ou energéticos, em seus entornos. Nesse contexto, através de modelos digitais, faz-se possivel testar diferentes configurações urbanas, com 
relação ao seu potencial para a geração de energia solar fotovoltaica.

\section{ENERGIA SOLAR FOTOVOLTAICA}

A radiação solar é a principal fonte de energia dos ecossistemas terrestres, sendo parte fundamental do processo de fotossíntese. Além disso, pode-se dizer que o sol é, indiretamente, responsável por fontes de energia renováveis como a energia eólica e a hidroelétrica. Entretanto, o uso direto da radiação solar, como fonte de energia pelo ser humano, dá-se principalmente através dos sistemas de aquecimento de água e da geração de energia elétrica (Associação Brasileira da Indústria Elétrica e Eletrônica, 2012).

A geração de energia elétrica a partir da radiação solar pode ocorrer de duas formas: através do efeito fotovoltaico, e nos sistemas CSP (Concentrated Solar Power). No primeiro caso, módulos feitos de um material semicondutor são expostos a luz, gerando uma corrente elétrica. Já no segundo, a luz solar é direcionada, através de uma série de espelhos, à uma torre que contém um fluido de trabalho, que será aquecido gerando vapor, fazendo rodar uma turbina e produzindo eletricidade (Associação Brasileira da Indústria Elétrica e Eletrônica, 2012).

No meio urbano, além do aquecimento da água, a geração de energia elétrica a partir do efeito fotovoltaico é a forma mais viável para o aproveitamento da radiação solar, reduzindo; e suprindo, parte ou totalmente, o consumo de energia elétrica dos edifícios. Existem muitas vantagens associadas à energia fotovoltaica, principalmente com relação aos impactos ambientais. Pode-se citar como exemplo, o fato de que a geração de eletricidade ocorre sem emissões. Vale destacar também que, a indústria responsável pela produção de componentes dos sistemas fotovoltaicos, visando contribuir com a imagem ambientalmente amigável dessa fonte de energia, tem investido em linhas de produção que gerem um menor impacto no ambiente, bem como na reciclagem dos componentes descartados (Associação Brasileira da Indústria Elétrica e Eletrônica, 2012). Somado a isso, a proximidade entre a geração e o consumo da eletricidade, nos casos de geração distribuída, é uma grande vantagem, já que reduz os custos e as perdas com a transmissão de energia. A não produção de ruídos e a funcionalidade estética dos sistemas também são atrativos, já que não corroboram com a poluição sonora e visual, na cidade (PEREIRA et al., 2017).

\section{ATUALIDADE \\ A SITUAÇÃO NO BRASIL}

O Brasil apresenta um grande potencial para a geração de energia solar fotovoltaica, devido à sua localização no globo. Na Alemanha, por exemplo, um dos países líderes na utilização da energia solar, o local mais ensolarado gera menos eletricidade do que o menos ensolarado do Brasil. É importante destacar que, com a regulamentação da Microgeração e Minigeração, em 2012, pela ANEEL (Agência Nacional de Energia Elétrica); e com os leilões específicos de energia solar fotovoltaica, realizados pelo Governo brasileiro, a partir de 2014, a energia solar fotovoltaica tem ganhando cada vez mais espaço no cenário nacional (PEREIRA et al., 2017). Entretanto, essa fonte de energia correspondia à 1,2\% da matriz energética do país, em 2019; referindo-se à produção de usinas solares de grande porte conectadas ao SIN (Sistema Interligado Nacional), (Associação Brasileira de Energia Solar Fotovoltaica - ABSOLAR, 2019). Em contraponto, na Alemanha, a energia solar fotovoltaica, no mesmo ano, correspondeu à $8,2 \%$ do consumo bruto de energia. (Fraunhofer ISE - Recent Facts about Photovoltaics in Germany, 2020) Isso mostra, que o Brasil ainda tem muito a crescer nesse setor.

Já em relação a geração distribuída, destaca-se um crescimento exponencial. Um dos principais motivos para isso é a redução crescente dos custos para a instalação dos painéis solares, bem como a mudança de direcionamento das concessionárias de energia, que passaram a considerar a energia solar fotovoltaica como uma oportunidade, já que a rede elétrica funciona como uma bateria que recebe os excedentes e supre a demanda, dos edifícios. Um outro ponto positivo é o fato de que, os meses de verão, quando a produção da energia fotovoltaica é maior, correspondem aos períodos de maior demanda da rede elétrica, o que contribuiria para diminuir a sobrecarga do sistema (PEREIRA et al., 2017). Além disso, em muitos lugares do país, as altas tarifas de eletricidade acabam por compensar o investimento em energia solar (Associação Brasileira da Indústria Elétrica e Eletrônica, 2012) (Figura 1).

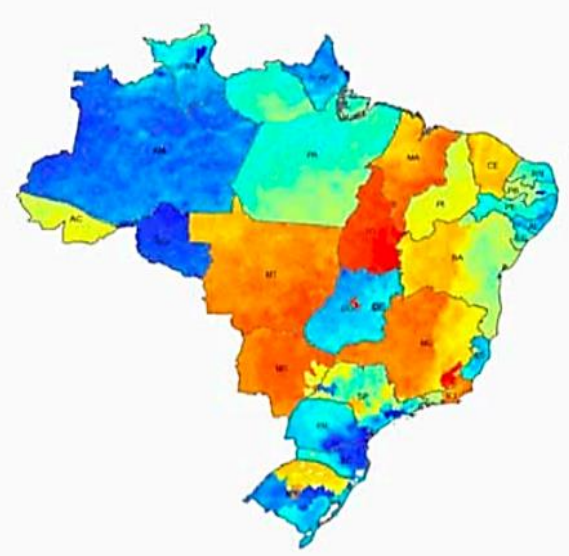

Figura 1: Mapa indicador de viabilidade econômica do investimento em energia solar para usuários de baixa tensão. Fonte: Proposta para Inserção da Energia Solar Fotovoltaica na Matriz Elétrica Brasileira.

Vale destacar que, além da energia solar fotovoltaica, a energia heliotérmica, ou CSP (Concentrated Solar Power), e o aquecimento da água para o uso doméstico, também estão presentes no Brasil. No segundo caso, sendo o Brasil o terceiro país do mundo em capacidade instalada para aquecimento de água, embora o trigésimo numa relação per capita (PEREIRA et al., 2017). Além disso, segundo a ABINEE, um outro grande benefício gerado pela implementação e crescimento da energia solar fotovoltaica, seria a geração de emprego, devido a necessidade de mão de obra para a instalação e manutenção dos painéis, e o desenvolvimento da indústria 
de componentes eletrônicos nacional, para a produção dos módulos solares.

\section{A SITUAÇÃO NA BAHIA}

Segundo a Secretaria de Desenvolvimento Econômico (SDE) da Bahia, em 2019 o estado foi líder na geração de energia solar e eólica, no país. Além disso, também aponta para um grande potencial para o crescimento da geração distribuída de energia solar, modelo adotado principalmente em áreas urbanas. Os dados levantados pela SDE apontam uma potência instalável de 177 MW(Megawatt) no setor de geração distribuída, como destaca o Informe Executivo Solar publicado pela secretaria em fevereiro de 2020.

Observa-se que, o estado da Bahia possui uma localização geográfica favorável ao uso da energia solar, já que sua área se situa em baixa latitude, diminuindo a variação entre a duração dos dias e das noites, ao longo das estações do ano. Além disso, a presença de chapadas e planícies no território é vantajosa para a instalação e o aproveitamento dos módulos fotovoltaicos (Atlas Solar Bahia, 2018).

No mapa abaixo, é possível notar que a Bahia, junto com os outros estados do Nordeste, bem como alguns das regiões Norte e Centro-Oeste, apresenta bom potencial de geração solar fotovoltaica (Figura 2).

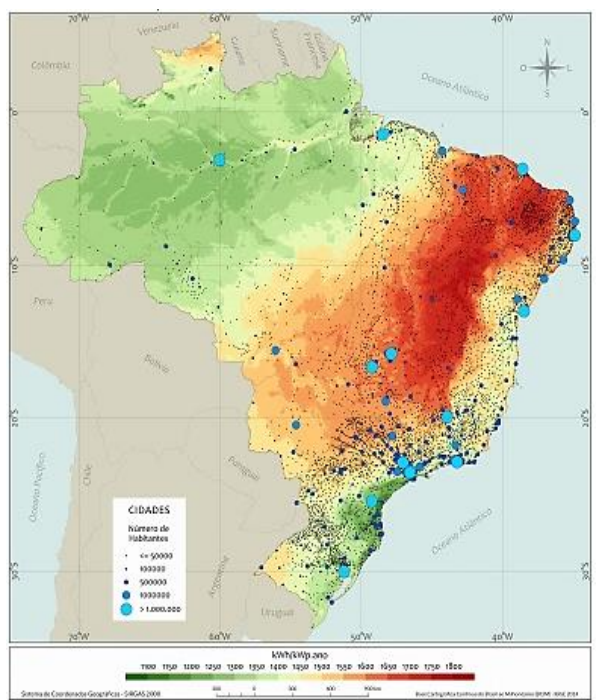

Figura 2: Mapa do potencial de geração solar fotovoltaica em território brasileiro. Fonte: Atlas Brasileiro de Energia Solar, p. 59.

Em relação à inserção da energia solar na matriz elétrica estadual, o Atlas Solar Bahia (2018) aponta que o principal empecilho está relacionado às distâncias entre as regiões com maior potencial e os grandes centros consumidores, além da falta de infraestrutura da rede elétrica. Entretanto, destaca que tais problemas podem ser solucionados devido à expansão do sistema elétrico para escoar a energia eólica, e a complementaridade desta com a solar, em algumas regiões do interior do estado. Já a geração distribuída apresenta vantagens quanto à instalação, em relação às usinas solares, uma vez que aproveitam estruturas existentes no ambiente urbano, como os telhados e fachadas dos prédios. Entretanto, apresentam um potencial de geração menor, tendo em vista que os painéis fotovoltaicos, podem sofrer com sombreamento indevido ou com inclinações não ideais. Isso reforça a necessidade de uma expansão inteligente do tecido urbano, que reduza o consumo energético e maximize o potencial de geração distribuída.

\section{A SITUAÇÃO EM SALVADOR}

A microrregião de Salvador, que, além da capital agrupa outras nove cidades baianas, apresenta, segundo o Atlas Solar Bahia (2018), a maior população, PIB, e consumo de energia, entre todas as microrregiões do Estado. Sendo assim, embora os dados do IBGE apontem para uma diminuição da taxa de aumento populacional nas últimas duas décadas, a população urbana de Salvador continua aumentando, fazendo-se necessária a busca por fontes renováveis de energia elétrica, como a solar fotovoltaica.

Nesse contexto, a prefeitura de Salvador lançou, em 2017, - Plano Salvador $360^{\circ}$, que visa unificar ações de diferentes secretarias do município. O plano apresenta oito eixos temáticos, valendo destacar o "Cidade Sustentável", que "foca na promoção de ações, cria estratégias e implanta soluções que garantem o desenvolvimento sustentável". Dentre os programas adotados no âmbito deste eixo, o mais relevante para o presente estudo é o Salvador Solar, coordenado pela Secretaria de Sustentabilidade Inovação e Resiliência (SECIS).

O programa Salvador Solar conta, até o presente momento, com duas iniciativas principais. A primeira foi a criação do IPTU Amarelo que, concede descontos de até $10 \%$ no IPTU (Imposto Predial e Territorial Urbano), a depender do quanto a energia solar fotovoltaica gerada em determinado edifício supre o consumo elétrico do mesmo. Além disso, há o incentivo do uso de painéis fotovoltaicos em prédios públicos. Vale destacar que a prefeitura já adotava uma medida similar ao IPTU Amarelo, o IPTU Verde, que, além de energias renováveis, abrange outras medidas que visem reduzir o impacto ambiental das edificações, como a coleta seletiva e gestão sustentável das águas.

É importante salientar que as medidas citadas anteriormente são amparadas pelo Plano Diretor de Desenvolvimento Urbano (PDDU), 2016; e pela Lei de Ordenamento de Uso e Ocupação do Solo (LOUOS), do mesmo ano. Ambas possuem artigos que incentivam a adoção de fontes renováveis de energia, como a solar fotovoltaica, como mostrado abaixo:

Art. 122. As diretrizes para o fornecimento de energia são:

I - garantia do pleno atendimento ao mercado consumidor de energia, assegurando níveis adequados de oferta e promovendo a conservação e utilização racional;

II - diversificação da matriz energética existente, estabelecendo medidas efetivas para a implementação do uso de fontes de energia renováveis $e$ 


compatíveis com as condições
ambientais;

III - promoção do desenvolvimento e utilização de novas tecnologias no uso de fontes alternativas e não convencionais de energia, de forma complementar, inclusive energia solar, tendo como objetivo empreendimentos residenciais e grandes equipamentos;

IV - definição de programa de medidas que induzam o uso de energia solar, sobretudo para o aquecimento de água;

V - monitoração da qualidade do serviço de energia elétrica, segundo os parâmetros definidos pela ANEEL. (PDDU - Salvador, 2016, p. 60 - 61).

Dessa maneira, é possível perceber que existem, a nível municipal, mecanismos que incentivam a utilização de energia solar fotovoltaica, bem como para aquecimento de água. Entretanto, como já citado anteriormente, no ambiente urbano a geração de energia pode ser prejudicada pelo sombreamento e inclinação dos painéis fotovoltaicos, o que demonstra a necessidade de que medidas que visem reduzir o consumo de eletricidade, bem como implantar fontes alternativas com a geração de energia distribuída, envolvam o planejamento do traçado urbano, e do uso e ocupação do solo, que, como será tratado a seguir, influenciam no potencial de geração.

\section{A ENERGIA FOTOVOLTAICA E O TRAÇADO URBANO}

De acordo com Cheng, Steemers, Montavon e Compagnon (2006), enquanto a verticalização nas cidades tem maior efeito sobre o potencial de geração fotovoltaica das coberturas, a densidade horizontal, ou seja, a taxa de ocupação do solo, reflete no potencial energético das fachadas. A disposição de edifícios e lotes, assim como a variação de gabaritos, também impactaria o potencial solar fotovoltaico da região.

Nestes estudos, se percebeu, por instância, que, quando há elevada taxa de ocupação, a implantação aleatória das edificações aliada à uniformidade de altura, se traduz em um maior aproveitamento da energia solar, principalmente devido às coberturas não sombreadas. Por outro lado, para baixas densidades horizontais, como as fachadas adquirem mais protagonismo, a diversificação de gabaritos acaba impactando positivamente. Dessa maneira, pode-se observar a interdependência entre os diversos aspectos que agem sobre o potencial fotovoltaico no ambiente urbano.

Montavon (2010), por sua vez, traz que a forma dos edifícios, tanto quanto sua distribuição no solo, influenciam o montante de energia fotovoltaica eles podem gerar. Além disso, propõe que a alta densidade urbana não necessariamente significa perda desse potencial, uma vez que existem diferentes maneiras de distribuir as edificações, o que pode aumentar o aproveitamento da incidência solar. A autora demonstra, por exemplo, que a organização de prédios em blocos que geram pátio interno, ao criar mais superfície de fachada e diminuir 0 sombreamento, torna-se mais eficiente em relação às distribuições nas quais os edifícios estão isolados, revelando uma possível tendência para o desenho urbano. Montavon conclui, também, que aumentar a taxa de ocupação geralmente não é uma boa alternativa.

Ratificando Montavon, Kanters e Wall (2014), colocam que, em contextos com baixa taxa de ocupação, a geometria da edificação impacta consideravelmente o potencial fotovoltaico, tendo seu efeito reduzido à medida que cresce o número de pavimentos. Também expõem que, na maioria dos casos, coberturas com baixa ou sem inclinação apresentam maior eficiência. A orientação do edifício, no entanto, não demonstra influência relevante. Para além, os autores destacam a densidade horizontal é a variável de maior influência sobre o potencial fotovoltaico da edificação.

\section{METODOLOGIA/ESTUDO DE CASO}

No campo da arquitetura existem, atualmente, diversas ferramentas para a projetação em ambiente digital. Os programas BIM, como já citado anteriormente, tem levado a projetos cada vez mais acurados, integrando os diferentes sistemas que compõem a obra. Além disso, softwares permitem avaliação dos critérios de desempenho das edificações, como o térmico, acústico, sonoro, energético, entre outros. O potencial para geração de energia solar fotovoltaica também pode ser avaliado por meio de programas computacionais de fácil interação. Sendo assim, para realizar o estudo de caso foram utilizados programas de desenho, modelagem, e edição de imagens.

\section{METODOLOGIA}

O primeiro passo do estudo foi identificar as áreas da cidade que seriam modeladas. Para tanto foi necessário fazer uma comparação entre a Lei de uso e Ordenamento do Solo (LOUOS) vigente, atualmente na cidade de Salvador, e aquela que foi substituída. Os bairros da cidade apresentam diversas zonas de uso, que entre outros parâmetros, define os tipos de construção permitidas em cada localização. Sendo assim, visando identificar as alterações ou permanências das zonas nas diferentes regiões da cidade, sobrepôs-se os mapas de zoneamento das duas leis. Esse processo foi realizado no software Inkscape, que foi escolhido por ser gratuito e de fácil utilização, tendo uma qualidade similar a outras opções pagas, como Corel Draw, Adobe llustrator, Adobe Photoshop.

Concomitante ao mapeamento, foi elaborada uma tabela contendo as alterações referentes ao zoneamento que ocorreram em cada bairro de Salvador. Dessa maneira foi possivel identificar em quais regiões ocorreram as mudanças mais significativas, dando especial atenção para os parâmetros:

1. Coeficiente de Aproveitamento: quociente entre a área construída total da edificação (soma das áreas de todos os pavimentos) e a área total do lote. 
2. Índice de Ocupação: quociente entre a área total projetada pela edificação no lote e a área total do lote.

Com as áreas escolhidas, partiu-se para a construção dos modelos digitais. Devido à falta de acesso à arquivos cartográficos oficiais das áreas, foi necessário criar arquivos vetoriais aproximados para basear a modelagem. Dessa maneira, à partir de Imagens de satélite das áreas, construiu-se um modelo vetorial das mesmas. A vetorização manual foi feita no software AutoCAD, escolhido por ter interoperabilidade com outros programas de desenho e modelagem, bem como pela familiaridade dos autores com este. Em seguida, o arquivo foi importado no software SketchUp, onde a modelagem foi executada. As análises do Potencial de geração de energia fotovoltaica foram realizadas no próprio SketchUp, através do plug-in LightUp, que, embora seja um programa para a renderização, também gera manchas de sombra e gráficos de radiação incidente em falsa cor.

A escolha do SketchUp deveu-se por vários motivos, dentre eles: a interface de fácil utilização, e o fácil aprendizado; a existência de vários plug-ins, que expandem as possibilidades de modelagem e análises do programa; por apresentar uma versão gratuita, que apresenta, praticamente, todas as ferramentas da versão paga.

\section{MODELAGEM}

Para o presente trabalho foram escolhidas três áreas de estudo, localizadas nos bairros de Stella Maris, Jardim Armação e Caminho das Árvores, tendo sido desenvolvidos seis modelos para cada uma. O primeiro, uma aproximação do estado atual, considerando os lotes, as vias e as edificações. Nos outros seis modelos, um quarteirão foi escolhido e dividido em lotes de, em média, $20 \mathrm{~m} \times 40 \mathrm{~m}$, sendo modificações feitas para adequar os lotes ao desenho do quarteirão. Em quatro modelos, os lotes foram divididos numa proporção $6: 3: 1$, para avaliar o Coeficiente de Aproveitamento (CA) e o índice de Ocupação (IO). Dessa maneira, em $60 \%$ dos lotes deveriam ser empregados os valores máximos, em $30 \%$ os médios, e em $10 \%$ os mínimos; isso para cada um dos dois parâmetros citados. Por fim, uma distribuição aleatória dos valores de CA e de $\mathrm{IO}$ foi adotada em dois dos modelos. Em outras palavras, os modelos podem ser assim descritos:

1. Modelo variando o Coeficiente de Aproveitamento; com o Índice de Ocupação fixo, LOUOS 2012;

2. Modelo variando o Índice de Ocupação, com o Coeficiente de Aproveitamento fixo, LOUOS 2012;

3. Modelo variando, tanto o Coeficiente de Aproveitamento, quanto o Índice de Ocupação, LOUOS 2012;

4. Modelo variando o Coeficiente de Aproveitamento, com o Índice de Ocupação fixo, LOUOS 2016;

5. Modelo variando o Índice de Ocupação, com o Coeficiente de aproveitamento fixo, LOUOS 2016.
6. Modelo variando, tanto o Coeficiente de Aproveitamento, quanto o Índice de Ocupação, LOUOS 2016;

\section{MODELOS DE STELLA MARIS}

Stella Maris fica na porção nordeste de Salvador, e faz fronteira com os bairros de Itapuã, Aeroporto e Alto do Coqueirinho. O bairro cresceu consideravelmente nas últimas três décadas, passando de um local de veraneio para um bairro residencial consolidado. De acordo com o Observatório de Bairros de Salvador, em 2010, Stella Maris possuía 20.641 habitantes, com uma densidade demográfica de 37,7 hab/ha (habitantes por hectare); e um total de 6.884 domicílios permanentes. Serviços como coleta de lixo; abastecimento de água; e esgotamento sanitário, estavam, todos, em mais de $80 \%$ das residências.

É importante destacar que o bairro apresenta uma baixa densidade demográfica, se comparado com outros bairros, com infraestrutura semelhante, como a Pituba $(147,2$ hab/ha); Vitória (164,26 hab/ha) e Centro (183,3 hab/ha). Além disso, pelo fato de predominarem residências unifamiliares, havendo poucos edifícios e torres multiresidenciais, o bairro apresenta possibilidades de crescimento.

A região modelada estava enquadrada na zona ZPR 2, em 2012; e passou em 2016, a estar nas zonas ZPR 1 (Zona predominantemente residencial 1) e ZCLMu (Zona Centralidade Linear Municipal). A modelagem foi feita com os parâmetros da ZCLMu, pois essa apresentou maiores mudanças em relação ao antigo zoneamento. Entretanto a área do estudo precisou extrapolar os limites dessa zona, para que fosse formada um quarteirão viável para o estudo (Figuras 3 e 4).

A seguir estão representados os comparativos entre os parâmetros vigentes em 2012 e 2016, utilizados na modelagem:

Tabela 1: Modelos variando o Coeficiente de Aproveitamento no bairro de Stella Maris. Fonte: Arquivo pessoal dos autores.

\begin{tabular}{|l|c|c|}
\hline & 2012 & 2016 \\
\hline Área do Lote $\left(\mathrm{m}^{2}\right)$ & 800,00 & 800,00 \\
\hline $\mathrm{N}^{0}$ de Lotes & 35 & 35 \\
\hline Índice de Ocup. & 0,5 & 0,7 \\
\hline Coef. de Aprov. Máx & 1,0 & 3,0 \\
\hline Coef. de Aprov. Bás. & 0,5 & 1,5 \\
\hline Coef. de Aprov. Mín. & 0,25 & 0,3 \\
\hline Recuo Frente $(\mathrm{m})$ & 6,0 & 4,0 \\
\hline Recuo Lateral $(\mathrm{m})$ & 2,0 & 1,5 \\
\hline Recuo Fundo $(\mathrm{m})$ & 3,0 & 2,5 \\
\hline
\end{tabular}


Tabela 2: Modelos variando o Índice de Ocupação no bairro de Stella Maris. Fonte: Arquivo pessoal dos autores.

\begin{tabular}{|l|c|c|}
\hline & 2012 & 2016 \\
\hline Área do Lote $\left(\mathrm{m}^{2}\right)$ & 800,00 & 800,00 \\
\hline $\mathrm{N}^{0}$ de Lotes & 35 & 35 \\
\hline Coef. de Aprov. & 0,5 & 1,5 \\
\hline Índice de Ocup. Máx. & 0,5 & 0,7 \\
\hline Índice de Ocup. Bás. & 0,3 & 0,5 \\
\hline Índice de Ocup. Mín. & 0,1 & 0,3 \\
\hline Recuo Frente (m) & 6,0 & 4,0 \\
\hline Recuo Lateral (m) & 2,0 & 1,5 \\
\hline Recuo Fundo (m) & 3,0 & 2,5 \\
\hline
\end{tabular}

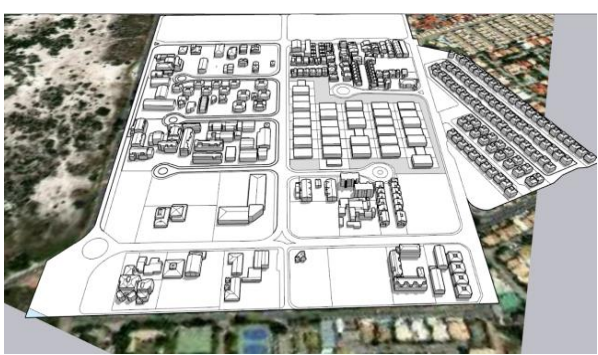

Figura 3: Modelo variando o Coeficiente de Aproveitamento, LOUOS 2012, conforme Tabela 1. Fonte: Arquivo pessoal dos autores.

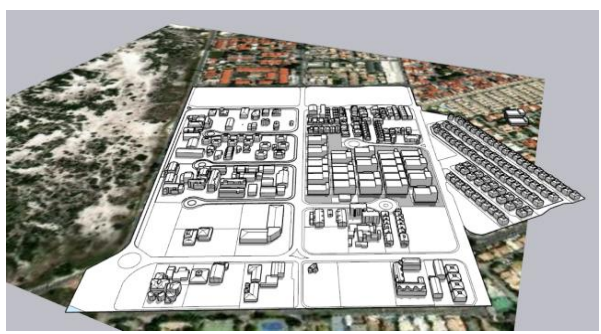

Figura 4: Modelo variando o índice de Ocupação, LOUOS 2016, conforme Tabela 2. Fonte: Arquivo pessoal dos autores.

\section{MODELOS DE JARDIM ARMAÇÃO}

O bairro de Jardim Armação possui baixa densidade populacional, cerca de 29 hab/ha, e está atrelado à Prefeitura-Bairro VI - Barra/Pituba. Em decorrência de sua localização na orla atlântica da cidade, o bairro é alvo de forte especulação imobiliária, sendo a construção de prédios residenciais a maior tendência na região.

Em 2010, segundo publicação da CONDER, o bairro possuía um total de 3.064 habitantes, sendo estes, em sua maioria, de classe média-alta com mais de 10 anos de estudo. Com cerca de $99,2 \%$ dos domicílios considerados particulares e permanentes, serviços como abastecimento de água e esgotamento sanitário chegam a quase $100 \%$ das moradias, o que contribui para que seu IDHM seja classificado como muito alto.

A região modelada se encontrava, em 2012, como ZPR-8 (Zona Predominantemente Residencial - 8), e passou, em 2016, a ser enquadrada na ZCLMu (Zona Centralidade Linear Municipal). Os lotes foram adequados ao formato do quarteirão pré-existente (Figura 5).

Tabela 3: Modelos variando o Índice de Ocupação no bairro de Jardim Armação. Fonte: Arquivo pessoal dos autores.

\begin{tabular}{|l|c|c|}
\hline & 2012 & 2016 \\
\hline Área do Lote $\left(\mathrm{m}^{2}\right)$ & $800,00-1403,77$ & $800,00-1403,77$ \\
\hline $\mathrm{N}^{0}$ de Lotes & 23 & 23 \\
\hline Coef. de Aprov. & 3 & 3 \\
\hline Índice de Ocup. Máx. & 0,5 & 0,7 \\
\hline Índice de Ocup. Bás. & 0,3 & 0,5 \\
\hline Índice de Ocup. Mín. & 0,2 & 0,3 \\
\hline Recuo Frente (m) & 5,0 & 4,0 \\
\hline Recuo Lateral (m) & 1,5 & 1,5 \\
\hline Recuo Fundo (m) & 3,0 & 2,5 \\
\hline
\end{tabular}

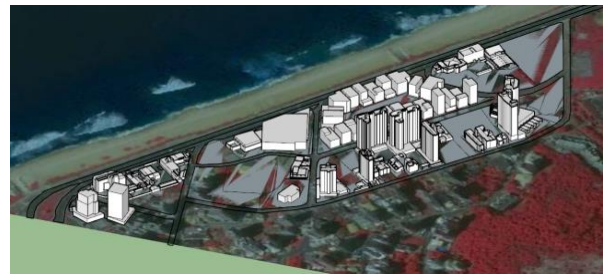

Figura 5: Modelo variando o Índice de Ocupação, LOUOS 2016, conforme Tabela 3. Fonte: Arquivo pessoal dos autores.

\section{MODELOS DE CAMINHO DAS ÁRVORES}

O Caminho das Árvores é um bairro considerado de classe média-alta, com baixa densidade populacional $(60,25$ hab/ha), principalmente quando comparado a outros bairros com perfil socioeconômico semelhante, o que pode ser associado à volumosa presença de casas como domicílios unifamiliares.

A região escolhida para modelagem (Alameda das Acácias e arredores), em especial, consiste de lojas e casas, ou seja, guarda terrenos com potencial para a construção de prédios e torres residenciais (Figura 6).

Em 2012, o quarteirão escolhido era denominado como CDL (Corredor Local), passando, em 2016, a ser uma ZCLMu (Zona Centralidade Linear Municipal). A área do entorno constituía uma ZEU (Zona Exclusivamente 
Residencial) e passou a ser uma ZPR-1 (Zona Predominantemente Residencial - 1).

Tabela 4: Modelos variando o Coeficiente de Aproveitamento no bairro de Caminho das Árvores. Fonte: Arquivo pessoal dos autores.

\begin{tabular}{|l|c|c|}
\hline & 2012 & 2016 \\
\hline Área do Lote $\left(\mathrm{m}^{2}\right)$ & $731,42-1283,59$ & $731,42-1283,59$ \\
\hline $\mathrm{N}^{\circ}$ de Lotes & 13 & 13 \\
\hline Índice de Ocup. & 0,5 & 0,7 \\
\hline Coef. de Aprov. Máx. & 2,0 & 3,0 \\
\hline Coef. de Aprov. Bás. & 1,0 & 1,5 \\
\hline Coef. de Aprov. Mín. & 0,5 & 0,7 \\
\hline Recuo Frente (m) & 5,0 & 4,0 \\
\hline Recuo Lateral (m) & 2,0 & 2,5 \\
\hline Recuo Fundo (m) & 3,0 & 1,5 \\
\hline
\end{tabular}

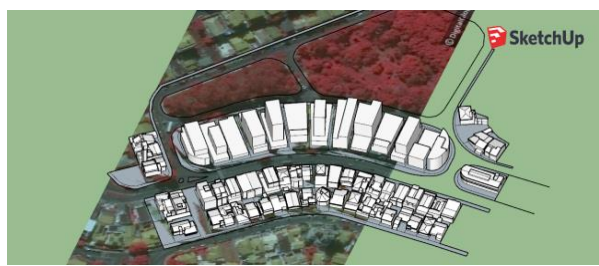

Figura 6: Modelo variando o Coeficiente de Aproveitamento, LOUOS 2016, conforme Tabela 4. Fonte: Arquivo pessoal dos autores.

\section{RESULTADOS}

Observando as tabelas comparativas da seção anterior, pode-se perceber que houve um aumento em relação aos Coeficientes de Aproveitamento e Índices de Ocupação. Em contrapartida, houve uma redução dos recuos exigidos dos limites do terreno. Realizando uma análise preliminar da sombra projetada dos edifícios modelados, verifica-se que, com relação ao potencial de geração de energia solar fotovoltaica:

1. Dos modelos em que os Coeficientes de Aproveitamento variam, o que segue os parâmetros de 2012 apresenta maior aproveitamento da radiação incidente.

2. Dos modelos em que os Índices de Ocupação variam, aquele que segue os parâmetros de 2012 apresenta maior aproveitamento da radiação incidente.

3. Dos modelos em que tanto os Índices de Ocupação quanto os Coeficientes de Aproveitamento variam, aquele que segue os parâmetros de 2012 apresenta maior aproveitamento da radiação incidente.

4. Dentre os modelos que seguem os parâmetros de 2016, aquele em que tanto os índices de
Ocupação quanto os Coeficientes de Aproveitamento variam é o que apresenta maior aproveitamento da radiação incidente.

5. Dentre os modelos que seguem os parâmetros de 2012, aquele em que tanto o Índice de Ocupação, quanto o Coeficiente de Aproveitamento variam apresenta aproveitamento semelhante àquele em que varia apenas o Índice de Ocupação, sendo esses dois os melhores.

Dessa maneira, levando em conta as análise de Cheng et al (2006), o potencial de geração de energia solar fotovoltaica nos envelopes dos prédios sofre perda, já que a área do lote em que se pode construir é maior, além disso as distâncias entre os prédios também serão reduzidas, fazendo com que o sombreamento de um sobre o outro aumente (Figuras 7 e 8). Contudo, o potencial de geração nas coberturas tende a aumentar, já que há mais superfície para a insolação. Por outro lado, há uma reconhecida tendência a verticalização na cidade, o que pode resultar em construções que ocupam uma menor porção do terreno a fim de subir mais pavimentos, resultando em prédios mais afastados.

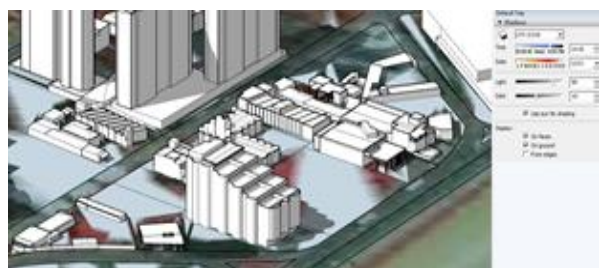

Figura 7: Sombras projetadas pelas edificações atualmente presentes no bairro de Jardim Armação. Fonte: Arquivo pessoal dos autores.

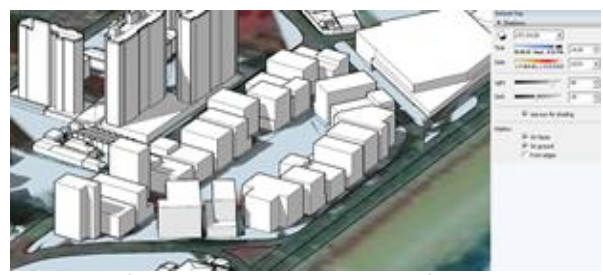

Figura 8: Sombras projetadas pelas edificações dispostas segundo novos parâmetros urbanísticos, dentro do modelo apresentado na Tabela 3. Fonte: Arquivo pessoal dos autores.

Vale também destacar que, os parâmetros atuais permitem uma maior densidade populacional, bem como predial. Como ressalta Montavon (2010), a densidade urbana pode não interferir negativamente no potencial de geração de energia fotovoltaica, sendo mais relevante a distribuição dos edifícios e suas formas. Nesse caso, a reavaliação dos recuos laterais, dilatando-os, teria grande impacto.

A partir das avaliações feitas, espera-se obter dados que ajudem a estabelecer diretrizes, atreladas à promoção da eficiência energética na cidade, para a determinação dos parâmetros urbanísticos. 


\section{DISCUSSÃO}

O presente estudo permite entender como as mudanças, ocorridas entre os anos de 2012 e 2016, nos parâmetros urbanísticos estabelecidos influenciariam na produção de energia fotovoltaica dentro do ambiente da cidade, o que é de suma importância, pois, dentro do atual contexto mundial, no qual busca-se construir cidades mais eficientes, tanto do ponto de vista socioeconômico, quanto ambiental, compreender como instrumentalizar tais parâmetros nesse sentido pode fazer grande diferença para a cidade como um todo.

Pode-se observar, contudo, que a extração do potencial fotovoltaico das edificações ainda é pouco levada em conta durante a deliberação das regras sob as quais se dá o assentamento dos imóveis em território urbano, o que colabora para a subutilização da energia solar.

Os modelos produzidos foram postos dentro de um contexto bem aproximado do real, respeitando, inclusive, geometrias prediais, desenhos e delimitações préexistentes e particulares de cada região. Isso permite obter dados que representam de forma mais fidedigna a situação encontrada e o impacto que a alteração dos parâmetros teve nas áreas estudadas. Pode-se, por exemplo, visualizar como o aumento do Índice de Ocupação e do Coeficiente de Aproveitamento mudam o perfil das edificações erigidas em bairros antes ocupados majoritariamente pela tipologia de casas. Além disso, as mudanças que ocorreram provocaram um maior sombreamento nas fachadas dos edifícios, reduzindo o potencial de geração de energia solar fotovoltaica nessas superfícies. Para conciliar a necessidade da ampliação das áreas edificáveis e o aproveitamento da energia solar via efeito fotovoltaico, uma redução do Índice de Ocupação, acompanhado de um aumento dos Coeficientes de Aproveitamento e dos Recuos seria uma opção viável.

Ressalta-se que os resultados apresentados podem vir a ser diferentes para outras configurações urbanas adotadas. Dessa forma, mais estudos como este são necessários para avaliar outras localidades da cidade e suas particularidades, de modo que o maior número possível de dados esteja disponível para as futuras alterações nas leis que regem o uso e a ocupação do espaço urbano.

\section{AGRADECIMENTOS}

Agradecemos o suporte da Fundação de Amparo à Pesquisa do Estado da Bahia (FAPESB) e da Universidade Federal da Bahia (UFBA) que viabilizaram a realização desse estudo.

\section{REFERÊNCIAS}

Associação Brasileira da Indústria Elétrica e Eletrônica (ABINEE). (2012). Propostas para Inserção da Energia Solar Fotovoltaica na Matriz Elétrica Brasileira. Disponível em: http://www.abinee.org.br/informac/arquivos/profotov.pdf

Atlas Solar: Bahia. (2018). Disponível em: http://200.187.9.65/docs/download/mapas/atlas-solar-Bahia2018.pdf

Cheng, V., Steemers, K., Montavon, M., \& Compagnon, R. (2006). Urban Form, Density and Solar Potential. Plea2006 - The 23rd Conference on Passive and Low Energy Architecture. Geneva, Switzerland, 1-6. Disponivel em: https://www.researchgate.net/publication/280037987

Decreto $n^{\circ} 29.100$ de 06 de novembro de 2017. (2017). Disponível em:

http://iptuverde.salvador.ba.gov.br/downloads/Decreto.pdf

Decreto $n^{\circ} 30.738$ de 21 de dezembro de 2018. (2018). Disponível em: http://www.iptuamarelo.salvador.ba.gov.br/downloads/DOM I PTU_Amarelo.pdf

Fraunhofer ISE. (2020). Recent Facts about Photovoltaics in Germany. Disponível em: https://www.ise.fraunhofer.de/content/dam/ise/en/documents/ publications/studies/recent-facts-about-photovoltaics-ingermany.pdf

Kanters, J., \& Wall, M. (2014). The impact of urban design decisions on net zero energy solar buildings in Sweden. Urban, Planning And Transport Research: An Open Access Journal, 2, 312-332. DOI: 10.1080/21650020.2014.893199

Montavon, M. (2010). Optimisation of Urban Form by the Evaluation of the Solar Potential. (2010). 255 f. (Tese de doutorado) - Faculté Environnement Naturel, Architectural Et Construit, École Polytechnique Fédérale de Lausanne, Lausanne. Disponível em: https://infoscience.epfl.ch/record/145897/files/EPFL_TH4657. pdf

Organização das Nações Unidas (ONU). (2020). Fórum global sobre cidades destaca necessidade de desenvolvimento urbano sustentável. Disponível em: https://nacoesunidas.org/forum-global-sobre-cidadesdestaca-necessidade-de-desenvolvimento-urbanosustentavel/

Organização das Nações Unidas (ONU). (2016). Nova Agenda Urbana. Disponivel em: http://www.habitat3.org/wpcontent/uploads/NUA-Portuguese-Brazil.pdf

Pereira, E. B. et al. (2017). Atlas brasileiro de energia solar. Disponivel http://urlib.net/rep/8JMKD3MGP3W34P/3PERDJE

Secretaria de Desenvolvimento Econômico do Estado da Bahia (SDE). (2020). Informe Executivo Solar. Disponível em: http://www.sde.ba.gov.br/wpcontent/uploads/2020/03/Informe-Executivo-Solar-Fevereiro2020.pdf 